九州大学学術情報リポジトリ

Kyushu University Institutional Repository

\title{
Understanding Crisis-based Communication on Environmental Protection in China : Mass Media and Individuals
}

Huang, Bo

School of Agricultural Economics and Rural Development, Renmin University of China

Yabe, Mitsuyasu

Laboratory of Environmental Life Economics, Division of International Agricultural Resource Economics and Business Administration, Faculty of Agriculture, Kyushu University

Xia, Wei

Michael Smurfit School of Business, University College Dublin

Zeng, Yinchu

School of Agricultural Economics and Rural Development, Renmin University of China

https://doi.org/10.5109/18860

出版情報: 九州大学大学院農学研究院紀要. 55 (2)，pp.419-426，2010-10-29. Faculty of Agriculture, Kyushu University

バージョン :

権利関係 : 


\title{
Understanding Crisis-based Communication on Environmental Protection in China: Mass Media and Individuals
}

\author{
Bo HUANG ${ }^{1}$, Mitsuyasu YABE ${ }^{2}$, Wei XIA ${ }^{3}$ \\ and Yinchu ZENG $^{4}$

\begin{abstract}
Laboratory of Environmental Life Economics, Division of International Agricultural Resource Economics and Business Administration, Department of Agricultural and Resource Economics,

Faculty of Agriculture, Kyushu University, Fukuoka 812-8581, Japan

(Received June 30, 2010 and accepted July 9, 2010)
\end{abstract}

\begin{abstract}
Beijing has been frequently stroked by sandstorms. During the occurrence of sandstorms, related information increased dramatically due to mass media. How did the mass media in China react to the sandstorm crisis? Did the crisis arouse public awareness of environmental protection? Were the majority willing to pay an environmental tax for air quality improvement? In response to these questions, the purpose of this study is to analyze the impacts of a short-term information explosion from mass media on individual's attitudes, perception and payment behavior. Two follow-up telephone interviews were carried out in Beijing before and after the sandstorm incidents. The empirical results suggest that mass media had created a surge of information available for individuals once sandstorms occurred. The information explosion had deepened residents' cognition of causes of sandstorms, government control measures and personal protection methods. $83 \%$ of our interviewees expressed their willingness to pay for an annual tax to support government against expanding sandy lands compared with $66.7 \%$ in the priori scenario. On average, households were willingness to pay 275 Chinese Yuan yearly. The empirical results confirm that information plays an important role in individual's perception of environmental protection and behavior selection.
\end{abstract}

\section{INTRODUCTION}

The sandstorms in China are products of worsening desertification in Inner Mongolia and other desert areas due to natural and human factors. In the past decade, Chinese government has sought to counter this violent environmental problem. A series of national programs have been launched to halt the spread of deserts, such as Sanbei Shelter-forest System Project, Returning farmland to forests Project, and the Sandstorm Source Control Project in Beijing and Tianjin. However, it seems that the country has not fundamentally reversed the trend of worsening desertification. According to Chinese officials ${ }^{1}$, the Chinese capital Beijing is now less than 250-kilometres from the encroaching desert. In the spring of 2010 a level 5 alarm was raised by the Chinese government due to severe sandstorms that plagued the Northern part of China which brought devastating damage and loss to people and their properties.

The crisis has bequeathed us with some questions. How did the mass media in China react to the sandstorms and severe damages? Did they provide useful and objective information to the public? How did individuals respond to the "yellow dust" in their daily life? Were they concerned with the news about sandstorm? How did they perceive the massive information from mass media

\footnotetext{
School of Agricultural Economics and Rural Development, Renmin University of China

${ }^{2}$ Laboratory of Environmental Life Economics, Division of International Agricultural Resource Economics and Business Administration, Faculty of Agriculture, Kyushu University

Michael Smurfit School of Business, University College Dublin

${ }^{4}$ School of Agricultural Economics and Rural Development, Renmin University of China

* Corresponding author (E-mail: yabe@agr.kyushu-u.ac.jp)
}

when a crisis took place? Were the majority willing to pay an environmental tax for improvement? Did the crisis arouse public awareness of environmental protection? There are rare studies on these topics except for some concerning with food hazards crisis for unavailability of empirical data (Wansink, 2004).

Therefore, the major purpose of this paper is to provide a better understanding of the crisis-based communication between mass media and residence on environment protection. At the center of the analysis is the notion that individuals may respond in different ways to environmental crisis and to a surge of related information from mass media. More specifically, this paper aims to explore how individual's perception and behavior changed after the sandstorm crisis under the influence of mass media from April to May in 2006 whose serverity and frequencies of sandstorms were comparable with the ones in 2010

The rest of the paper is organized as follows. Section 2 defined the theoretical model and analytical framework. Section 3 presented the data source and illustrated some important descriptive features. Section 4 focused on information release from mass media about sandstorms and individual's personal experiences. Section 5 investigated individual's concerns, attitudes, and perception of sandstorms. A Wilcoxon signed-rank test was applied to explore whether there were significant changes in perception after sandstorm took place. Section 6 explored individual's protection measures, changes in payment behavior as well as the relationship between individual's perception and payment behavior. Section 7 concludes and provides implications for policy decisions. 


\section{METHODOLOGY}

\section{Theoretical model ${ }^{2}$}

Following Laffont (1989)'s theory on individual's behavior under uncertainty, a number of analysis tools such as the notions of risk aversion, the measure of risk and the concept of information structure are derived in a stochastic environment under the rationality hypothesis.

Let $s \in(1, \cdots, S)$ denotes a set of states of nature, while there is a set of acts for individuals denoted by $a$ $\in(1, \cdots, A)$. The combination of the two leads to a consequence $x(a, s)$. The target function of an act $u(x(a, s), s)$ is derived, assumed to be bounded and non-decreasing.

Therefore, the rational behavior of an individual is to maximize the expected utility function in the absence of relevant information services:

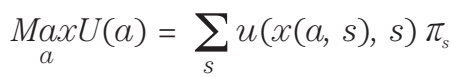

where $\pi_{s}$ denotes an unconditional probability measure in the states of nature $s$ and $a_{0}^{*}$ is the optimal solution.

In the presence of information, the set of acts an individual will take with prior information $(m)$ from certain sources changes to $a_{m}$, and the consequences will be $x\left(a_{m}, s\right)$. The joint probability matrix of states of nature $(\mathrm{s})$ with specific information $(m)$ thus is:

An information structure with noise $\Omega_{m}$ can be perceived as a posteriori probability for a specific signal $m$, mapping into a space of information $(1, \cdots, M)$ in the states of nature $s \in(1, \cdots, S)^{3}$. Useful information may change individual's information structure and their rational decision.

Compared with prior information structure $\Omega_{0}$, the new information structure $\Omega_{m}$ enrolls in new useful information $m$ of which the individuals can take advantage. In this situation, the expected utility function for maximizing is given by:

$$
\max _{a(\cdot)} U\left(a_{m}\right)=\sum_{m} \sum_{s} u\left(x\left(a_{m}, s\right), s\right) j_{s m}
$$

where the target function of an act $a_{m}$ is $u\left(x\left(a_{m}, s\right), s\right)$.

Based on the assumption that individuals will take full advantage of all prior information, equation 2 can be re-written as:

$$
\max _{a(\cdot)} U\left(a_{m}\right)=\sum_{m} \sum_{s} v\left(a_{m}, s\right) q_{s m} q_{m}
$$

where $q_{s m}$ is the conditional probability for specific information $m$. As $q_{m}$ is the unconditional probability for $m$ (see Table 1), the equation 3 can be easily transformed:

$$
\max _{a(\cdot)} U\left(a_{m}\right)=\sum_{m} \sum_{s} v\left(a_{m}, s\right) q_{s m}
$$

where the optimal action will be $\alpha_{m}^{*}$. From equation 2, it can be easily derived

$$
\begin{aligned}
U\left(a_{m}^{*}\right)=\sum_{m} \sum_{s} u\left(x\left(a_{m}^{*} s\right), s\right) j_{s m} \\
\geq \sum_{m} \sum_{s} u\left(x\left(a_{0}^{*} s\right), s\right) j_{s m}=U\left(a_{0}^{*}\right)
\end{aligned}
$$

Hence $U\left(a_{m}^{*}\right) \geq U\left(a_{0}^{*}\right)$, and the value of information $m$ should be.

$$
\omega_{m}=U\left(a_{m}^{*}\right)-U\left(a_{0}^{*}\right) \geq 0
$$

The equation 6 indicates that useful information will have positive effects for decision making which calls for researches on the outcomes of information release.

Sometimes, the availability of abundant information shocked people in a relatively short time, which is supposed to transform individual's information structure. To simplify the problem, it is assumed that people have the same ability to handle diverse information. The priori information structure and action of an individual are denoted as $\Omega_{k}$ and $a_{k}$ respectively, which together lead to a consequence $x\left(a_{k}, s\right)$. When there is an explosion of information, the new information structure and action will turn to be $\Omega_{h}$ and $a_{h}$ respectively, resulting in consequence $x\left(a_{h}, s\right)$. Based on equation 2, the maximum expected functions of priori and posteriori scenarios would be as follows:

$$
\begin{aligned}
& \max _{a(\cdot)} U\left(a_{k}\right)=\sum_{k} \sum_{s} u\left(x\left(a_{k}, s\right), s\right) j_{s k} \\
& \max _{a(\cdot)} U\left(a_{h}\right)=\sum_{h} \sum_{s} u\left(x\left(a_{h}, s\right), s\right) j_{s h}
\end{aligned}
$$

Table 1. Joint probability matrix for states of nature with prior information

\begin{tabular}{c|cccccc|c}
\hline$J$ & 1 & 2 & $\cdots$ & $m$ & $\cdots$ & $M$ & Probability $(s)$ \\
\hline 1 & $j_{11}$ & $j_{12}$ & $\cdots$ & $j_{1 m}$ & $\cdots$ & $j_{1 M}$ & $\pi_{1}$ \\
2 & $j_{21}$ & $j_{22}$ & $\cdots$ & $j_{2 m}$ & $\cdots$ & $j_{2 M}$ & $\pi_{2}$ \\
$\vdots$ & $\vdots$ & $\vdots$ & $\ddots$ & $\vdots$ & $\ddots$ & $\vdots$ & $\vdots$ \\
$s$ & $j_{s 1}$ & $j_{s 2}$ & $\cdots$ & $j_{s m}$ & $\cdots$ & $j_{s M}$ & $\pi_{s}$ \\
$\vdots$ & $\vdots$ & $\vdots$ & $\ddots$ & $\vdots$ & $\ddots$ & $\vdots$ & $\vdots$ \\
$S$ & $j_{S 1}$ & $j_{s 2}$ & $\cdots$ & $j_{S m}$ & $\cdots$ & $j_{S M}$ & $\pi_{s}$ \\
\hline Probability $(m)$ & $q_{1}$ & $q_{2}$ & $\cdots$ & $q_{m}$ & $\cdots$ & $q_{M}$ & 1 \\
\hline
\end{tabular}

Notes: $q_{m}$ is the unconditional probability with specific information $m$, and $j_{s m}$ is the joint probability of the states of nature $s$ with specific information $m$. Sources: based on Dong (2005) 
where $a_{k}^{*}$ and $a_{h}^{*}$ are the optimal actions respectively, and $j_{s k}$ is the joint probability of the behavior $a_{k}$ which individual may adopt before she is affected by new information in the state of nature $s$, and $j_{\text {sh }}$ is the joint probability of the behavior $a_{h}$ which individual may adopt after she is affected by new information in the state of nature $s$.

Similarly with equation 5 , the conclusion $U\left(a_{h}^{*}\right) \geq$ $U\left(a_{k}^{*}\right)$ would be tenable and the value of a surge in information $\omega_{k \rightarrow h}$ would be calculated as:

$$
\omega_{k \rightarrow h}=U\left(a_{h}^{*}\right)-U\left(a_{k}^{*}\right) \geq 0
$$

The equation 9 provides the theoretical evidence that a surge in valuable information would have positive effects on personal decision making. For the empirical study of this research, personal knowledge $I$ (including awareness and attitudes of environment protection, perception of sandstorms, etc.) is granted for valuable information.

Furthermore, assume that before the Sandstorm Source Control Project in Beijing and Tianjin had carried out, the air quality in Beijing was $q^{0}$, and $\mathrm{Z}$ was a composite commodity of all other public good whose value equals to a tax charged to households. With the program, the air quality improved from $q^{0}$ to $q^{1}\left(q^{0}<q^{1}\right)$ and the supply of other public good changed from $Z^{0}$ to $Z^{1}$ at the same time. Individual's willingness to pay for air quality is given by the compensation surplus (see Bergstrom et al. 2004):

$$
W T P=C=e\left(P, Q^{0}, Z^{0}, u^{0}\right)-e\left(P, Q^{1}, Z^{1}, u^{1}\right)
$$

where $\mathrm{P}$ is a vector of prices for all market goods.

As the restricted income $(e)$ can be divided into disposable income $\left(e^{*}\right)$ and the tax $\mathrm{Z}$, the equation 13 can be rewritten as:

$$
W T P=C=e^{*}\left(P, Q^{0}, Z^{0}, u^{0}\right)-e^{*}\left(P, Q^{1}, Z^{1}, u^{1}\right)+Z^{0}-Z^{1}
$$

As the value of information is a function of utility changes (see equation 6), the equation 14 may change to the form as follows, a surge in valuable information $I_{k \rightarrow h}$ :

$$
\begin{aligned}
& W T P=C \\
& \quad=\left[e^{*}\left(P, Q^{0}, Z^{0}, u^{0}\right)-e^{*}\left(P, Q^{1}, Z^{1}, u^{1}\right)\right] \mid I_{k \rightarrow h}+Z^{0}-Z^{1}
\end{aligned}
$$

The equation 15 indicates the theoretical relationship between the value of information and willingness to pay for improvements in a certain environmental quality.

\section{Analytical Framework}

Figure 1 presented the relationship between information, perception (information structure), and behavior at the individual level in the classical scenario based on the theoretical model. Individuals may have different attitudes and perception when their information structures are transformed. As a consequence, better knowl-

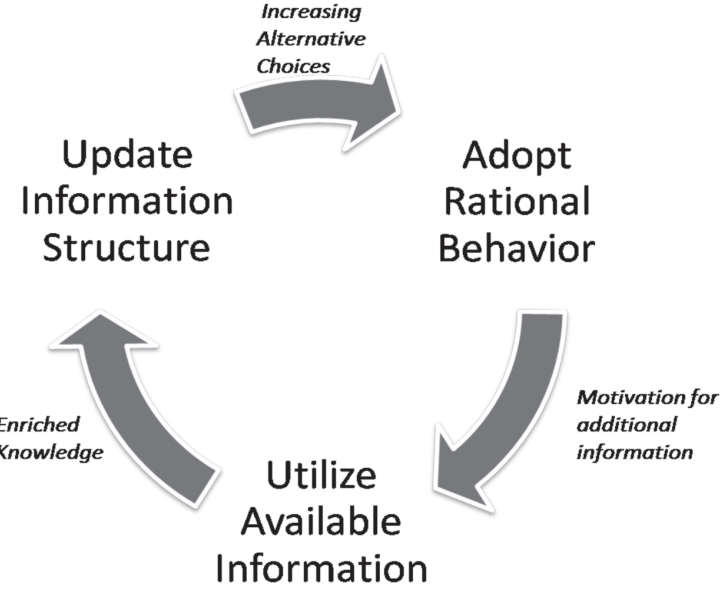

Fig. 1. The relationship between Information, Perception (Information Structure) and Behavior.

Notes: The negative effects of information is omitted for simplicity here

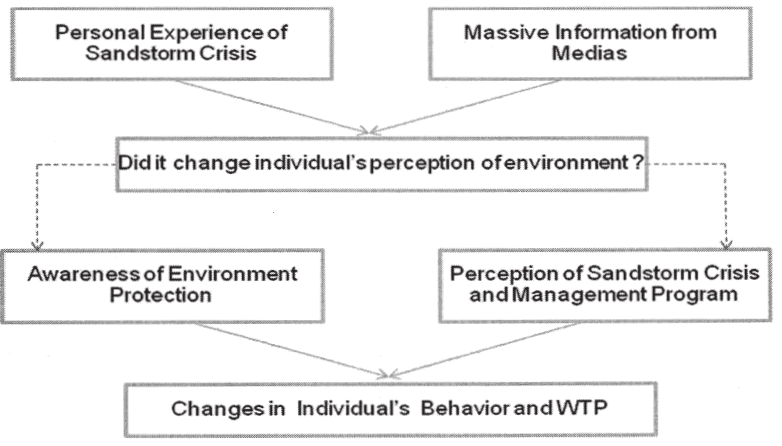

Fig. 2. Framework for case study.

edge enables individuals to adopt rational behavior with more reliable evidences. This positive feedback may encourage individuals to acquire more valuable information voluntarily for next rounds. Thus, information plays a vital role in individual economic activities throughout the whole decision making process.

A case study was conducted to analyze the role of information on individual's attitudes and behavior towards environmental crisis (Figure 2). To magnify the information effects, the study mainly focused on the surge of information both from internet and individual's personal experiences during the occurrence of sandstorms.

\section{DATA}

The data were collected from two follow-up telephone interviews made before and after the sandstorm crisis during the months of January, February and April 2006. From the 100 residential telephone numbers that were randomly chosen by the computer, only 18 persons participated in the interviews twice. It seems that the $18 \%$ response rate was much lower that the face-to-face interviews and the drop-off and pick-up questionnaire 
Table 2. Socio-demographic characteristics of sample

\begin{tabular}{ll}
\hline \multicolumn{1}{c}{ Variable Description } & Sample Characteristics \\
\hline Average age & 45 \\
\hline Education & $50 \%$ female \\
& $28 \%$ have undergraduate degree and above \\
& $11 \%$ have a certificate or diploma \\
& $39 \%$ completed high school \\
& $22 \%$ not complete high school \\
\hline \multirow{2}{*}{ Occupation } & $6 \%$ government officials \\
& $6 \%$ teachers \\
& $38 \%$ company employees \\
& $11 \%$ students \\
& $39 \%$ retired \\
\hline Monthly expenditure per person & $17 \%$ under 300 RMB \\
& $11 \%$ under 500 RMB \\
& $33 \%$ under 700 RMB \\
& $28 \%$ under 1000 RMB \\
& $11 \%$ above 1000 RMB \\
& \\
& \\
& \\
& \\
& \\
& \\
& \\
& \\
&
\end{tabular}

approach.

During the interviews, the participants were asked about their personal experiences and perception on sandstorm crisis together with willingness to pay for air quality improvement. The basic socio-demographic characteristics of the sample are summarized in Table 2. There were not many differences between the census and our survey except for the annual expenditure per person.

The proportion of lower income family seemed much larger in our survey as compared with the population census carried out by Beijing government in 2006. About $60 \%$ of our participants reported that the annual expenditure per person for his family was under 8400 RMBs. This is in contrast with the population census in which $60 \%$ of all the households indicated an expenditure of 11810 RMBs per person annually. The result possibly leads to bias and leaves much room for explanation and investigation $^{4}$.

\section{A SURVEY FOR INFORMATION}

\section{Mass media}

The intensive news from mass media (Television programs, newspapers, radios, magazines, internet, etc) had created a surge of information available for individuals during the occurrence of sandstorm. Internet was taken as a proxy for mass media due to its availability for statistics compared with other media sources.

Using the biggest Chinese search engine www.baidu. com, a total of 2140 entries were found for the "2006, Beijing, Sandstorms" compared to 245 entries prior to sandstorm outbreaks. A total of 943 entries were retrieved using the "2006, Beijing, Sandstorms, March" as keywords, while 1540 entries for "2006, Beijing, Sandstorms, April". Based on this information, it appears that there was a significant increase in the amount of related information between March and April ${ }^{5}$. A lot of comprehensive websites created special columns for the event, such as $S O H U^{6}, S I N A^{7}$, which provided relevant information about scientific knowledge on sandstorms, dusty weather forecasts, and personal protective measures.

Sandstorms stoke Beijing for six times between March 22 and April 25, (March 24 $4^{\text {th }}-25^{\text {th }}, 26^{\text {th }}-28^{\text {th }}$, April $\left.5^{\text {th }}-8^{\text {th }}, 9^{\text {th }}-11^{\text {th }}, 16^{\text {th }}-19^{\text {th }}, 21^{\text {th }}-23^{\text {th }},\right)$ in the year of 2006 . Daily entries in the special column of the website of Sina during this period were displayed in Figure 3. The entries increased significantly on the next day, and a sharp surge was observed from $16^{\text {th }}$ to $19^{\text {th }}$ April. It would be very interesting to discover the causes. On the afternoon of $16^{\text {th }}$ April, the worst sandstorm leveled at five swept over Beijing, throwing down approximately 336 thousand tons of dusts. The sandstorm event drew much attention during the $6^{\text {th }}$ National Environmental Protection Conference that was held on the $17^{\text {th }}$ and $19^{\text {th }}$ of April, which was attended by Premier Wen Jiabao.

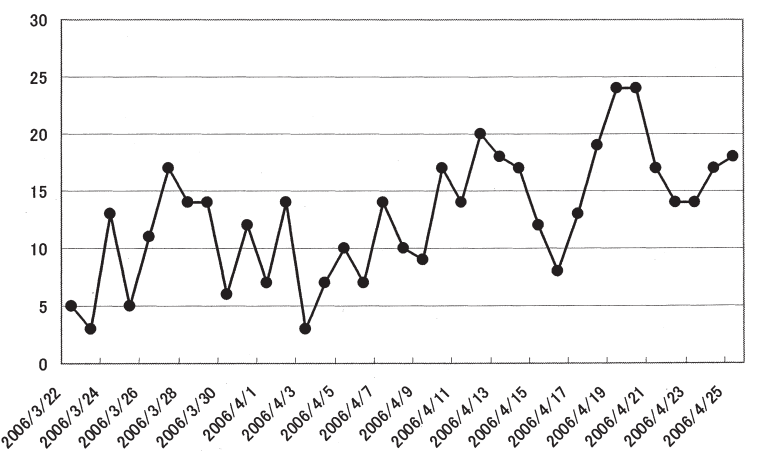

Fig. 3. Entries about sandstorm crisis found on the special column of Sina during March $2^{\text {nd }}$ and April $25^{\text {th }}$. Data source: sorted from http://news.sina.com.cn/z/scbcha 


\section{Personal experiences}

The BBC news said, "Millions of residents woke to find their city covered in a thin film of yellow dust after the storm blew in from the border of China and Mongolia. Some are wearing face masks and hospitals reported increased numbers of patients with breathing problems." In our survey, all of the participants expressed that sandstorms had great influence of their daily life in four aspects: decreased outdoor activities, cloudy indoor air and dusty rooms, and causing breathing problems.

In sum, a surge of information from mass media assuredly took place and individuals had great awareness of the harm which sandstorms brought to them from their personal experiences.

\section{INDIVIDUAL'S CONCERNS, ATTITUDES AND PERCEPTION}

\section{Individual's concerns about information}

Base on our survey, most participants showed great concerns about the information related to sandstorms. Out of the eighteen participants, fifteen were worried about the reduced visibility and potential hazards to their health. In contrast, two participants didn't pay much attention on these issues because they had been used to sandstorm events every spring. Only one participant was too busy to take in such kind of information.

To get better knowledge about their interests in relevant information, the questionnaire was classified into five categories: sandstorm forecasting, causes of sandstorms, progress of sandstorm source control programs, personal protection measures and national environmental policy ${ }^{8}$.

Figure 4 showed that participants paid closest attention to "effective sandstorm forecast". When asked about

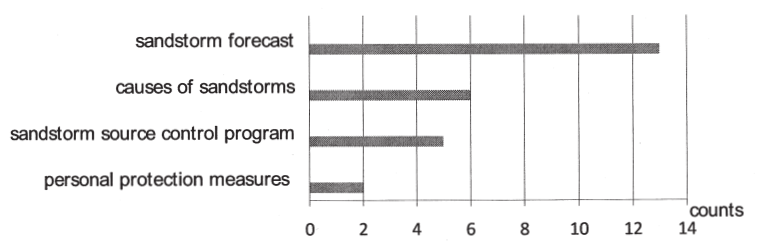

Fig. 4. Indivisual concerns about information relevant to sandstorms.

the information services they are longing to have in the future, the "scientific explanation of sandstorm formation" ranked the first, followed by "sandstorm forecasting" and "progress in control programs". It seems that there is an urgent need for the dissemination of scientific information about environment protection to the public.

Furthermore, our survey shows that television program and newspaper were the main media for people to gain information ${ }^{9}$. Eight of eighteen participants preferred either the TV program or newspaper, while the other 6 participants would like to take advantage of both media. Only one participant preferred three media types by including the internet as source of information.

\section{Individual' perception of sandstorm crisis}

In this pilot survey, open questions were used to get more detailed information. The results are summarized in Table 3.

The majority of the participants believed that climate factors like hard-wind and drought weather were the causes of sandstorm. Such beliefs were similar to those opinions made by scientists (Littmann, 1991; Zhou, 2001; Zhou and Zhang, 2009). While other factors such as human activities, and dust from Mongolia were ranked

Table 3. Individual's attitudes and perception of sandstorms

\begin{tabular}{|c|c|}
\hline Questions & Answers \\
\hline $\begin{array}{l}\text { What causes sandstorms in your opinion? } \\
\text { (multiple choice) }\end{array}$ & $\begin{array}{l}7 \text { persons mentioned climate change (winds, dry climate, limited } \\
\text { rainfalls) } \\
6 \text { persons mentioned Human activities } \\
5 \text { persons mentioned dust from foreign countries } \\
4 \text { persons mentioned dust from massive construction site around } \\
3 \text { persons mentioned weak governmental management } \\
3 \text { persons mentioned insufficient city greening } \\
2 \text { persons mentioned difficulty in desert control } \\
2 \text { persons didn't know }\end{array}$ \\
\hline $\begin{array}{l}\text { Do you agree that our government has taken } \\
\text { effective measures for sandstorm control? }\end{array}$ & $44 \%$ disagreed \\
\hline $\begin{array}{l}\text { Do you know the Sandstorm Source Control } \\
\text { Project in Beijing and Tianjing? }\end{array}$ & $78 \%$ heard about it before \\
\hline $\begin{array}{l}\text { Do you know any other projects related to } \\
\text { sandstorm control by the government? } \\
\text { (multiple choice) }\end{array}$ & $\begin{array}{l}6 \text { persons mentioned the Returning farmland to forests Project } \\
4 \text { persons mentioned the Sanbei Shelter-forest System Project } \\
1 \text { persons mentioned the Early Warning System for Sandstorms } \\
5 \text { persons didn't know } \\
2 \text { persons No answers }\end{array}$ \\
\hline $\begin{array}{l}\text { Do you know the Early Warning System for } \\
\text { Sandstorms in Beijing? }\end{array}$ & $44 \%$ said yes \\
\hline
\end{tabular}


second and third respectively by the participants.

Based on individual's personal account of their daily life experience, some believed that the massive construction sites around Beijing may have contributed to the sandstorm crisis. It was reported ${ }^{10}$ at the same time that the scale of construction sites in Beijing broke its historical record as large as 1300 million square meters, which is greater than the sum in Europe.

Almost $80 \%$ of the participants had have heard of the Sandstorm Source Control Project in Beijing and Tianjing. About $72 \%$ of the participants could enumerate some other relevant projects, including the Returning farmland to forests Project, the Sanbei Shelter-forest System Project and the Early Warning System for Sandstorms.

Many participants have indicated that they had heard of the Early Warning System for Sandstorm from the mass media during the occurrence of severest sandstorm in April $16^{\text {th }}$ and $19^{\text {th }} 2006$.

In general, it seems that individuals had taken in useful information from mass media and their personal experiences as their source of knowledge.

\section{Changes in individual's perception and attitudes}

It is of great interest to investigate whether individual's attitudes and perception of sandstorm crisis changed significantly in terms of priori and post periods. The non-parametric statistical hypothesis test-Wilcoxon signed-rank test was conducted for our repeated measurements for a single sample ${ }^{11}$. Using SPSS version 18, the data was examined and listed in Table 4 . The results showed that individual's willingness to pay for an annual tax and their concerns about air quality forecast had both significantly increased after the sandstorm crisis. However, there weren't enough evidences to prove that individual became more concerned about environmental problems after the occurrence of environmental crisis

\section{INDIVIDUAL'S PAYMENT BEHAVIOR}

\section{Aversion behaviour}

In the face of severe air pollution by sandstorms, 16 out of 18 participants had taken personal protection measures to the best of their abilities. Twelve participants reported to have reduced their outdoor activities. Four participants indicated that they minimized opening their windows, Four participants reported that they wore face mask or hats outside. Only two stated that they had never taken any protection measures as they got used to the dusty weather every spring.

\section{Changes in WTP by new information}

As it is showed in the theoretical section (section 2.1 ), the conclusion suggested that the value of additional useful information should be reflected on the changes of WTP. In the survey, participants were asked whether they were willing to pay an annual tax to support the government in fighting with desertification. If they agreed, it was followed by another question that elicits the amount which they would like to pay.

$83 \%$ of our interviewees expressed their willingness to pay after sandstorm breakouts compared $66.7 \%$ priori. On average, households were willing to pay as much as 275 Chinese Yuan yearly after sandstorm breaks in

Table 4. Statistical test for the changes in individual's environmental concerns after sandstorm outbreaks

\begin{tabular}{lcc}
\hline Variables & Z-value & P-value \\
\hline WTP & -2.670 & $0.008^{* * *}$ \\
Concerns about air quality forecast & -2.810 & $0.005^{* * *}$ \\
Concerns about city greening & -0.816 & 0.414 \\
Concerns about auto emission & -1.155 & 0.248 \\
Concerns about industrial emission & 0.248 & 0.305 \\
Concerns about breathing problems & -0.237 & 0.813 \\
\hline
\end{tabular}

Notes: *** indicates it is significant at 99\% confidence level.

Table 5. Compared groups of WTPs with open end questions

\begin{tabular}{|c|c|c|c|c|c|c|c|}
\hline \multicolumn{4}{|c|}{ Group1 (WTP Changed) } & \multicolumn{4}{|c|}{ Group2 (WTP didn't change) } \\
\hline No. & Before & After & Change & No. & Before & After & Change \\
\hline 1 & 100 & 200 & 100 & 3 & 200 & 200 & 0 \\
\hline 2 & 100 & 200 & 100 & 6 & 500 & 500 & 0 \\
\hline 4 & 150 & 300 & 150 & 10 & 0 & 0 & 0 \\
\hline 5 & 100 & 1000 & 900 & 13 & 1000 & 1000 & 0 \\
\hline 7 & 0 & 200 & 200 & 14 & 0 & 0 & 0 \\
\hline 8 & 0 & 50 & 50 & 16 & 500 & 500 & 0 \\
\hline 9 & 120 & 300 & 180 & 17 & 0 & 0 & 0 \\
\hline 11 & 0 & 50 & 50 & 18 & 400 & 400 & 0 \\
\hline 12 & 120 & 200 & 80 & & & & \\
\hline 15 & 100 & 120 & 20 & & & & \\
\hline \multicolumn{2}{|c|}{ Sample size } & \multicolumn{2}{|l|}{10} & \multicolumn{2}{|c|}{ Sample size } & \multicolumn{2}{|l|}{8} \\
\hline
\end{tabular}


comparison with 188 Chinese Yuan priori. Comparing the paired results of two surveys, ten participants changed their mind in the amount they were willing to pay, while other eight stayed the same. Three participants who were not willing to pay anything before have changed their minds after the occurrence of sandstorms Based on the statistical test, it was observed that individuals' willingness to pay had changed significantly after the crisis, as indicated in Table 4.

\section{The relationship between Concerns and WTP}

Table 6 presented the statistical results of the relationship between changes in Concerns and WTP using SPSS with 2 independent samples test. It seems that individual's WTP changed consistently with their increasing concern for air quality forecast (sandstorm outbreak), and breathing problems. As mentioned previously, unpleasant feeling in breathing made people much more aware of the potential hazards of sandstorm to their health, and therefore they are willing to pay more for improvement.

\section{CONCLUSIONS AND POLICY IMPLICATIONS}

The objective of this study is to analyze the impacts of a short-term information explosion from mass media on individual's attitudes, perception and payment behavior with respect to sandstorm crisis in Beijing.

The results show that mass media (Television programs, newspapers, radios, magazines, internet, etc) had created a surge of information available for individuals as soon as sandstorm crisis occurred. All of our participants had negative personal experiences on the hazards of sandstorm. They autonomously obtained valuable information mainly from televisions and newspapers, including air quality forecast, sandstorm source control progress and personal protection measures. The short-term information explosion had deepened residents' cognition of causes of sandstorms, government control measures and personal protection methods.

In the view of most of the participants, climate factors (drought weather in spring, strong winds) were the first causes of sandstorms. It was followed by human activities, construction sites and dust from foreign countries. The last two factors were very unique because they suggest that individuals had taken in useful information as knowledge storage. In addition, most participants in the survey had acquainted themselves with governmentrelated policies, including Sandstorm Source Control
Project in Beijing and Tianjing, the Returning farmland to forests Project, and the Sanbei Shelter-forest System Project.

In the face of severe air pollution due to sandstorms, $89 \%$ of our participants had taken personal protection measures to the best of their abilities. They had to eliminate outdoor activities, wear face mask or hats outside, and minimize window-opening. Due to their concern about sandstorm hazards, $83 \%$ of our interviewees expressed willingness to pay for an annual tax to support government fights against expanding sandy lands after sandstorm breakouts compared with $66.7 \%$ priori scenario. On average, households were willing to pay as much as 275 Chinese Yuan yearly afterwards, in comparison with 188 Chinese Yuan in priori scenario. It was also observed that individuals' concerns about air quality forecast and willingness to pay for air quality improvement had significantly increased after the crisis. It seems that individual's WTP changed consistently with their increasing concern for air quality forecast and breathing problems. However, there weren't enough evidences to prove that individual became more concerned about environmental problems after the occurrence of environmental crisis.

Our results confirm that information plays an important role in individual's perception of environmental protection and behavior selections. With these insights, suggestions are made for pre-crisis preparation and postcrisis response as follows.

The pre-crisis preparation may involve with four aspects: (1) promoting environmental awareness national wide; (2) providing scientific knowledge of environmental protection for the public; (3) integrating different communication channels; (4) honoring non-governmental efforts in environmental protection, including individuals and NGOs. After the occurrence of an environmental crisis, it is necessary for the government to provide open communication, live forecasting services, as well as information on crisis control progress through mass media.

However, there are some issues left for future discussing. This research focused solely on the positive effects of short-term information explosion without considering the decreasing value of information in the long term. In addition, this research is a sort of pilot survey with limited sample size, which calls for more evidences from large samples. It is noted as well that the distribution of income group for our sample seemed to be differ-

Table 6. The relationship between changes in individual's concern and WTP

\begin{tabular}{l|cc}
\hline \multicolumn{1}{c|}{ Variables } & Kendall's tau-b value & P-value \\
\hline Concerns in air quality forecast & 0.350 & $0.091^{*}$ \\
Concerns in city greening & 0.172 & 0.450 \\
Concerns in auto emission & -0.066 & 0.764 \\
Concerns in industrial emission & 0.147 & 0.495 \\
Concerns in breathing problems & 0.353 & $0.060^{*}$ \\
\hline
\end{tabular}

Notes: * indicates it is significant at $90 \%$ confidence level. 
ent from the population census by Beijing government. It is not clear as to the causes of this bias, which may leave us space for further discussion.

BBC news: http://news.bbc.co.uk/2/hi/asia-pacific/1883494.stm

2 Refer to Loffont (1989) and Qian et al. (2009) for more detailed information.

${ }^{3}$ Laffont (1989) and Qian et al. (2009) called the relevant information as signals

${ }^{4}$ The following factors might cause the bias: phone interview, strategy response to questions about income or expenditure, proportion of female interviewees.

5 The search work was conducted by the authors at the end of March and April, 2006. If you type in the same keywords recently, the results will turn out far different.

${ }^{6}$ Special column "Say hello again to sandstorms"://news.sohu. com/s2006/06shachenbao/

7 Special column "Attention to the sandstorm crisis in 2006": http://news.sina.com.cn/z/scbcha/

${ }_{8}$ Participants were notified that they can have multiple choices for this question.

9 Television and newspaper counted for nine times separately from a multiple-choice question. Internet appeared for four times as well.

${ }^{10}$ Newspaper JING:

http://www.beelink.com.cn/20060406/2057078.shtml (access date: 04-20-2010)

${ }^{11}$ It can be used as an alternative method instead of paired student-T test when the population cannot be assumed to be normally distributed.

\section{ACKNOWLEDGMENTS}

This paper is funded by the national natural science fund project of china titled "External Benefits of Agroforestry's CVM Theory and Metheod of Evaluation"(No.70473092), and the major program of Chinese Ministry of Education titled "The Study of Modern Agriculture Development" (No.07JZD0007).

\section{REFERENCES}

Bergstrom, J. C., Boyle, K. J. and Yabe, M. 2004 Trading Taxes vs Paying Taxes to Value and Finance and Public Environmental Goods. Environmental and Resource Economics. 28(4): 533-549

Bennett, J. and Adamowicz, W. 2001 Some Fundamentals of Environmental Choice Modelling. In: J. Bennett and R. Blamey (Editors), The Choice Modelling Approach to Environmental Valuation. Edward Elgar, United Kingdom, Cheltenham, 37-72

Huang B., Yabe M. 2010 A Study on the Sandstorm Source Control Project in and around Beijing and Tianjin. Sci. Bull. Fac. Agr., Kyushu Univ. 65 (1): 23-30

KeizoN. 2002 An Introduction to Information Economics Toyo Keizai Inc Press(Japan)

Laffont J. J. 1989 The economics of uncertainty and information, MIT Press (France)

Littmann, T. 1991 Dust storm frequency in Asia: Climatic control and variability. International Journal of Climatology, 11(4): 393-412

Morrison M. and MacDonald D. H. 2006 Valuing Biodiversity: A Comparison of Compensating Surplus and Compensating Tax Reallocation, available at:http://www.webmeets.com/ ere/wc3/prog/getpdf.asp?pid=702\&pdf=/files/papers/ ERE/WC3/702/Morrison_and_HattonMc Donald. pdf (access date: 04-20-2010)

Qian C., Chen J. and Nakagawa T. 2009 Comparison of Two Information Structures with Noise and Its Application to Bayes Decision Analysis, Quality Technology and Quantitative Management 6(1): 1-10

Wansink, B. 2004 Consumer Reactions to Food Safety Crises Advances in Food and Nutrition Research 48: 103-150

Yabe M., Kosaku N., Motoyuki G. 2000 Economic Evaluation of the Aso Grassland Landscape by Contingent Valuation Method: Comparative Analysis of Donation and Taxreallocation Payment Vehicles, Studies in Regional Science. $30(1)$ : 183-195

Zhang, X. Z. 2006 The Northeast Asia Sandstorm of Spring in 2006 Meteorological Press (China)

Zijiang Z. 2001 Blowing-sand and sandstorm in China in recent 45 years, Quaternary Sciences (in Chinese) 21(1): 9-17

Zijiang Z. and Guocai Z. 2009 Typical severe dust storms in northern China during 1954-2002. Chinese Science Bulletin. 48(21): 2366-2370 